\title{
CASTELLI MEDIEVALI IN SICILIA. Dai Bizantini ai Normanni. Ferdinando Maurici
}

\author{
(Collana La Pietra Visuta. Sellerio editore, Palermo 1992. Ilustrado, 432 pp.)
}

\begin{abstract}
Ferdinando Maurici nos presenta en esta obra una aproximación a la evolución del poblamiento en Sicilia entre los siglos VII y XIII y a la influencia fundamental que tuvieron en ella las diferentes fases de encastillamiento protagonizadas por las tres formaciones sociales que conquistaron y dominaron la isla: bizantinos, musulmanes y normandos, hasta el advenimiento de Federico II.
\end{abstract}

Su investigación la basa en una exhaustiva y rigurosa consulta de la documentación escrita -muy escasa hasta el siglo Xl- y de las crónicas redactadas por historiadores y geógrafos musulmanes y cristianos contemporáneos a los acontecimientos, y en un minucioso estudio toponímico de los cientos de lugares implicados en su estudio. A esto hay que añadir su esfuerzo por integrar los escasos datos aportados por la aún reciente Arqueología Medieval siciliana, basándose sobre todo en algunas prospecciones superficiales, ya que hasta la fecha de redacción del libro eran escasísimas las excavaciones realizadas.

El libro consta de dos partes. En la primera, el autor expone en cinco capítulos su investigación y conclusiones sobre los procesos de encastellamiento que se produjeron en la isla durante la Alta Edad Media. El primer y segundo capítulo están dedicados respectivamente, a la etapa bizantina y musulmana, y los últimos tres al período normando, fase en la que las fuentes escritas son mucho más abundantes. La segunda parte consiste en un pormenorizado inventario de las fortificaciones normandas que aún perviven (I 36 en total, en mejor o peor estado), en el que además de una fotografía de cada una de ellas, Maurici añade toda la documentación que ha podido recopilar sobre sus orígenes y evolución así como una descripción de su estructura, planta, y materiales de construcción. Un excelente apéndice bibliográfico y documental completa la obra.

La base argumental de la que parte Maurici y en la que fundamenta todas sus conclusiones es que, en Sicilia, más que en el resto de las regiones meridionales de la Península Itálica, la herencia de la Antigüedad constituirá la base de la distribución y de la tipología de los asentamientos durante toda la Alta Edad Media. La red urbana antigua será el armazón a partir del cual se organizará el asentamiento en época bizantina. Una estructura debilitada, pero no anulada por el proceso de ruralización y disgregación del poblamiento, documentado por la Arqueología entre los siglos IV y $\vee$ d.C.

El retroceso del frente bizantino desde África a Sicilia y la creación del Tema siciliano en 692-695, provocó la militarización de la Sociedad y de la Administración. Los ataques musulmanes se agudizaron durante la primera mitad del siglo VIII, y sólo la grave rebelión beréber concedió a Sicilia una tregua de medio siglo, coincidiendo con el reinado de Constantino $\vee$ que organizó una resistencia enérgica al expansionismo islámico, favorecida por la crisis que provocó la caída de la dinastía Omeya.

Según el autor, se puede hablar en Sicilia de un "precoce incastellamento in età tematica: ...la fortunata formula di 'révolution castrale' è pienamente adattabile alla Sicilia dell'VIII secolo". Esta gran operación de fortificación fue programada y realizada por el Estado, encontrándose referencias posteriores en la obra de los cronistas musulmanes An Nuwayri (siglo XIII) e Ibn al Athir (Siglo XII-XIII), que hablan de un diseño, implícitamente orgánico y planificado, de fortificación ejecutado por los Rum.

Cuando se reanudaron los ataques en 827, los aglabíes encontraron un país muy diferente del que saquearon impunemente en sus incursiones de los siglos VII y VIII: Sicilia contaba con decenas de asentamientos fortificados que los musulmanes debieron conquistar o forzar a la rendición uno por uno, durante una serie de campañas que en conjunto duraron más de 70 años.

El estudio de las crónicas árabes referidas a la conquista demuestra, según el autor, que la realizada por los bizantinos fue una "revolución" que encontró la base de su grandeza y eficacia en la elección de emplazamientos que en gran parte habían sido heredados de la colonización griega, de la presencia púnica en Sicilia Occidental y de la Prehistoria y Protohistoria indígena. La estrategia defensiva que adoptaron los bizantinos consistía básicamente en crear una serie de centros fortificados formando al mismo tiempo un cuerpo de intervención móvil que pudiera enfrentarse velozmente al enemigo donde fuera necesario. Así, mientras fueron fortificados todos los puertos principales (Siracusa, Palermo, Mesina, Agrigento, Lilibeo), las antiguas acrópolis del interior (Enna, Lentini, Agira, Centuripe, Taormina) y nuevos asentamientos en posición estratégica, se situó un grueso contingente armado en el Castrum Hennae, un enclave inaccesible en el centro geográfico de la isla, ganglio vital para la defensa del Tema.

En conclusión, la denominada por el autor "precoz revolución castral de la etapa temática" condicionará fuertemente el desarrollo del poblamiento siciliano posterior: el diseño de una jerarquía de asentamientos fortificados en los que se concentrará la población, actuará como un formidable instrumento de control fiscal, político y social, y como un vehículo eficaz de profunda unificación cultural de la isla. 
Una forma particularmente interesante de hábitat, aunque poco estudiado, es el rupestre, documentado al menos desde el siglo VII y que además tuvo que adquirir cierta envergadura, ya que las fuentes árabes de la conquista hacen referencia explícita a grupos de grutas (giran) habitadas, y en un caso, a una "fortaleza de grutas" (hisn al giran). Un ejemplo es la reocupación del asentamiento rupestre de Pantalica, en Caltabellotta, centro de la Edad del Bronce y del Hierro, con una necrópolis compuesta por más de 5000 pequeñas grutas excavadas en las paredes calcáreas de una garganta del río Anapo, que fueron reutilizadas y acondicionadas como viviendas e iglesias en el siglo VII. Auténticas fortalezas rupestres son la Pietra de Calatasudemi (Agrigento) y el Castello di Cava d'Ispica, en cuyos alrededores se han recogido materiales con una cronología que va desde la Edad del Bronce hasta la Baja Edad Media.

En relación a este tipo de hábitat, el autor considera que hay que rechazar "l'immagine romanticheggiante, più volte ripetuta dalla letteratura storica ed archeologica, della fuga spontanea di intere popolazioni verso siti alti e difendibili di fronte alla minaccia musulmana". Para Maurici, en la Sicilia bizantina, el poder del Estado o mejor, del Emperador, representado por una jerarquía rigidísima sometida a un severo control, no podía permitir iniciativas que no fueran aquellas emanadas directamente de su voluntad. Por lo tanto, la construcción de cualquier obra defensiva era el resultado de una operación administrativa, no de la decisión individual de un privado. Por lo que estas experiencias rupestres hay que enmarcarlas dentro de una tendencia tan marginal y modesta que era tolerada.

En cuanto a la conquista musulmana, según el autor no fue muy "destructiva": Comparando el censo de ciudades y fortalezas bizantinas con la lista de los centros urbanos que ofrece el geógrafo Muqaddasi en el siglo $\mathrm{Xl}$, y sobre todo con la documentación de los siglos XI y $X \mathrm{XI}$, las ausencias resultan prácticamente irrelevantes.

Además, la invasión aglabí de la isla será el inicio de un significativo renacimiento urbano, sobre todo en Sicilia Occidental (Val di Mazara), primera región conquistada, que sufrirá un rápido proceso de islamización. Palermo, conquistada en el 83I, gracias a su posición (al NO de la isla) y a la presencia de un buen puerto natural que aseguraba la conexión con Ifriqiya, fue elegida como nueva capital.

La penetración musulmana fue más lenta e inicialmente menos masiva en el SE de Sicilia (Val di Noto). Allí la resistencia bizantina fue aplastada sólo con la caída de la capital temática, Siracusa, en el 878, lo que contribuyó a retrasar el proceso de aculturación. Por último, al Norte, la región que ocupa el Val Demone, seguirá siendo durante mucho tiempo un núcleo de resistencia bizantina. La historia siciliana al menos desde mitad del siglo IX al $X$ está marcada por la coexistencia de dos áreas políticamente diferentes y enfrentadas entre sí al menos hasta la toma del asentamiento fortificado de Taormina, al NE del Val Demone en el año 902. Además, este reducto bizantino en la isla representó para los musulmanes la frontera tras la cual, rebeldes y vencidos pudieron refugiarse durante las numerosas luchas intestinas que se producían entre los invasores. En Taormina buscaron refugio muchos árabes de Palermo en 900, cuando el emir de Ifriqiya intervino en apoyo de los beréberes de Agrigento, en lucha contra la arabizada Palermo. Idéntica situación se planteó en el 913, durante la revuelta que estalló en Palermo contra los emisarios del nuevo poder fatimí.

La información arqueológica sobre esta primera etapa musulmana es escasa. Las prospecciones superficiales de algunos de los asentamientos fortificados atribuidos por las fuentes a la etapa islámica, o bien de aquellos de origen griego, púnico o romano reutilizados por los musulmanes, no han conseguido individualizar la fase emiral, pues la inexistencia de clasificaciones tipológicas hace muy difícil el reconocimiento en el terreno de los materiales de los siglos $I X$ y $X$.

Una vez que la presencia fatimí en la isla parecía estable, el califa al Mu'izz (952-975) mandó a sus oficiales en Sicilia "di edificare in ciascuno iqlim (distretto) una città fortificata (madina hasina) con una moschea gami ed un minbar e di obbligar a la popolazione di ogni iqlim a soggiornare nella città non permettendo che vivessero sparpagliati per le campagne". Esta perentoria orden de concentración del hábitat parecería justificada en primer lugar, por la alarma suscitada por un desembarco bizantino en 962 y por la sublevación del Val Demone.

El problema que según el autor cabe plantearse es en qué medida se cumplió el mandato de al Mu'izz. Según An Nuwayri, el emir siciliano Ahmad se apresuró a ejecutar la orden del Califa. Para comprobar la veracidad de esta afirmación, Maurici integra los datos de la lista de ciudades proporcionada por el geógrafo al Muqaddasi en 988 (bastante parcial e incompleta, pues casi ignora los centros del interior y puertos de origen antiguo como Lilibeo, Marsala o Milazzo, añadiendo por el contrario centros costeros o próximos al mar de escasa importancia) que recoge 30 centros en total, con datos conocidos a través de las crónicas árabes de la invasión y sobre todo por la primera documentación proporcionada por los normandos (narraciones de la conquista y diplomas de fundaciones de iglesias) añadiéndose así otros 50 nombres. De estos centros, la mitad tienen origen antiguo o son citados en etapa bizantina.

Las eventuales fundaciones musulmanas no se pueden identificar, ya que incluso topónimos claramente árabes (Caltabellotta, Catalfaro, Catalvuturo) fueron acuñados para designar centros ya existentes. A pesar de esto, la información toponímica no es menospreciada por el autor, que realiza un vaciado de la documentación posterior al siglo Xl y sobre todo un pormenorizado rastreo en las hojas cartográficas de la isla buscando topónimos de raíz árabe que indiquen asentamientos fortificados; los resultados, al menos cuantitativamente, son relevantes: Los topónimos más frecuentes (unos 40) son los formados con qal'a (qila en plural), que designa generalmente una fortaleza particularmente inaccesible y de grandes 
dimensiones. Menos numerosos (I 3 en total) son los topónimos en qasr, que designaba en origen un edificio fortificado, aunque evoluciona y pasa a denominar barrios urbanos fortificados. Topónimos originados a partir de burg, equivalente a torre, el autor contabiliza 17. Finalmente, son 30 los topónimos construidos a partir de la Kunya, el sobrenombre honorífico de un individuo.

En todo caso, concluye el autor, sumando las mudun de Muqaddasi, los castra de la primera documentación normanda y aun teniendo en modesta consideración el dato toponímico, la cifra de 100 centros fortificados en época musulmana no parece absurda o exagerada.

Aunque este simple dato numérico no es suficiente por sí solo para demostrar el éxito del plan del califa Mu'izz. La precisa orden emanada hacia el 966-67, eliminaba en teoría el hábitat abierto e intercalar, diseñando un mapa del poblamiento compuesto por una serie de asentamientos fortificados y en posición eminente que concentraban en ellos a la población. Sin embargo, la existencia del hábitat rural no fortificado, parece confirmado, en primer lugar por An Nuwayri, que lo llama qarya, sinónimo de rahal o manzil, y también por el testimonio, tardío pero no por esto desdeñable de Ibn Khaldun que, narrando la conquista normanda de la isla, subraya la facilidad con la cual fueron ocupadas las alquerías a diferencia de la extrema resistencia opuesta por los centros fortificados.

En definitiva, el autor enmarca el problema insistiendo de nuevo, sobre la existencia de continuidad con la Antigüedad: El esquema general del asentamiento en la Sicilia musulmana estaría constituido esencialmente por las ciudades portuarias y por las acrópolis de la Sicilia bizantina y por lo tanto, antigua: "In una terra de antichissima civiltà urbana, nella quale l'età bizantina segnò una vera e propria 'révolution castrale', gli spazi per una nuova, originale e massiccia ondata di incastellamenti che non si sovrapponesse in molti casi ad una complessissima stratificazione preesistente, non erano certamente larghissimi". La larga guerra de conquista no habría destruido esta estructura, mientras que la afirmación de la dominación musulmana habría supuesto la reorganización de las relaciones entre las diversas zonas de la isla, privilegiándose en ella al Val di Mazara, y a sus ciudades costeras, especialmente Palermo. El modelo de organización territorial elaborado por los fatimíes en Sicilia sería parecido al del al- Andalus descrito por A.Bazzana y P.Guichard: división del territorio en Iqlim, cada uno con su capital, sede del poder político y religioso, y con una población que se distribuiría en alquerías (rahal en Sicilia). El mandato de al Mu'izz habría conseguido un "incastellamento parziale" del hábitat, potenciando militar y administrativamente los grados más altos de esta jerarquía, utilizando asentamientos preexistentes más que construyendo nuevas mudun.

A pesar de este esquema general, el autor advierte del error que conllevaría el considerar a la Sicilia de entre el siglo IX y primera mitad del XI, como un conjunto orgánico y unitario, y el interpretar las iniciativas de fortificación musulmanas sólo como respuesta a amenazas externas, en el cuadro de la rivalidad secular con
Bizancio y la Cristiandad: La Sicilia musulmana hace frente durante toda su existencia a luchas intestinas motivadas por problemas étnicos, políticos, religiosos y dinásticos. La construcción de la Kalsa, la "Ciudadela de los elegidos" como refugio del poder fatimí dentro de la propia Palermo, es el símbolo tangible de esta compleja realidad.

Los primeros trabajos arqueológicos parecen avalar esta situación, descubriendo una tipología de hábitat fortificado diversificada, que no se limita a la madina hasina deseada por el Califa. Se han documentado, con una cronología aproximada de finales del siglo $X$ y primera mitad del Xl, importantes asentamientos fortificados de altura (lato, Entella, Calatrasi, Calathamet, Cinisi), identificándose con la misma cronología lo que el autor define como "siti-rifugio": qila de factura tosca, aislados, inaccesibles, y sin centro habitado (Pizzo Monaco, Calatagabuni, Calatamauro). Todos ellos se sitúan en el Val di Mazara, la zona más islamizada de la isla.

Junto a esta diversidad del hábitat fortificado, la abundante toponimia rural basada en rahal y manzil le sugieren al autor una frecuente presencia de asentamientos abiertos ya en el siglo X, planteando una hipótesis de la que él mismo pide futuras verificaciones: "...che la rete dei casali musulmani e quindi normanni ricalchi almeno in parte la frammentazione dell'habitat rurale tipica d'età tardo-romana e pretematica".

En cualquier caso, el supuesto modelo territorial puesto en marcha por el poder fatimí, si llegó alguna vez a realizarse, no fue por mucho tiempo, ya que después de 1040 Sicilia sufrió un proceso de violenta fragmentación política comparable, según Maurici, al desarrollo de las taifas ibéricas. Cuando desembarcan los normandos, la isla está dividida en tres reinos, y en una especie de "república aristocrática" con sede en Palermo.

Hacia los centros más importantes: la capital, Palermo, las civitates ennnoblecidas por la renovada presencia de un obispado, los castra más ilustres por su historia y más importantes por recursos económicos, población y defensas, se dirigió básicamente el flujo de latinos que llegaron a Sicilia. La discriminación social, racial, cultural y jurídica de los vencidos, encontrará expresión en la progresiva expulsión de las etnias sometidas de los centros fortificados y de su marginación en villorrios indefensos y en los rabats a extramuros, y por lo tanto en su concentración en áreas bien delimitadas y controlables, inicialmente de forma voluntaria, como única posibilidad de escapar al progrom y a la violencia latina, más tarde, siendo programado directamente por la monarquía, con la creación de la Archidiócesis de Moreale, en cuyos extensísimos territorios en el Val di Mazara -una especie de "gran reserva"-, la completa aculturación y cristianización de los campesinos dependientes era sólo una cuestión de tiempo.

Contemporáneamente, y en relación directa con la organización del territorio y de los hombres -consolidación de un fuerte poder central, asentamiento de un esta- 
mento feudal no muy numeroso-, la conquista normanda introduce en Sicilia el castellum, la fortaleza feudal. Sede, símbolo e instrumento del nuevo poder (del rey, del dominator, del obispo), la mole del castillo se impone casi siempre a asentamientos preexistentes, a menudo, como primer acto del vencedor después de la rendición de los habitantes, para el control, mantenimiento del nuevo orden, defension de li chrestien y opresión de los indígenas. La relación entre asentamiento fortificado, urbs, civitas, castrum, chora, qal'a y fortaleza, (castellum e incluso castrum), es prácticamente total y conduce directamente a los caracteres originarios de la conquista: la supremacía de la corona que reservó para sí las principales ciudades y tierras costeras y algunas posiciones clave en el interior; el asentamiento de pocas, potentes familias feudales, parapetadas en sus dominios y fortificadas en castillos urbanos. Su número, si bien no es escaso (en el siglo Xll se han comprobado unos 60 castillos, pero probablemente serían más de 100), está lejos del que, en el siglo XIV, producirá el encastillamiento menudo sobre los feudos. La ausencia casi completa de pequeños castillos edificados cerca de las centenares de aldeas o caseríos existentes, es indicio de la debilidad de la pequeña aristocracia caballeresca, de los milites y de algunos barones de la más antigua feudalidad siciliana. Los cognominia toponímicos de muchas familias, en muchos casos ligados a importantes oppida y castillos, evidencian como mucho la condición de milites castri dotados con un modesto feudo donde no residen y por lo tanto donde no tienen necesidad, además de posibilidad económica y jurídica, de erigir una residencia fortificada.

Según el autor, una vez analizada la política exterior y militar de los Altavilla (Haute Ville), resulta históricamente errado buscar una estrategia "nacionalista" detrás de la existencia de quizás un centenar de fortalezas en la Sicilia normanda. La defensa del "confín" costero contra el peligro musulmán (que las fuentes normandas nos muestran efectivamente tan sólo en manera contingente y limitada), era una exigencia sin duda de segundo orden respecto a los opresivos problemas de organización interna impuestos por la conquista. Y si el poder monárquico reservó para el patrimonio real todas o casi todas las más importantes y fortificadas ciudades costeras, no fue en primer lugar por necesidades defensivas frente a un potencial o hipotético peligro mediterráneo. Asentamientos fortificados y fortalezas son la prueba, no de la unidad interna contrapuesta al peligro externo, como sucederá al inicio del siglo XIII con Federico II, sino más bien instrumento y símbolo de una realidad social, cultural y jurídica caracterizada por enfrentamientos violentos.

A pesar de esto, para Maurici, el papel jugado por el Estado en la organización del poblamiento es, en la Alta Edad Media, fundamental: "...Sarà lo stato o, più correttamente gli stati a programmare ed attuare -o al meno controllare rigidamente- le grandi trasformazioni nell'assetto dell'insediamento: Saranno gli stati ad imporre il proprio suggello a distruzioni e costruzioni di abitati". La etapa de Federico II supondrá en este sentido, la exasperación en negativo de este poder. La ruptura de los delicados mecanismos de la convivencia desigual y el intento de regresar al orden normando protagonizado por Federico II, tuvieron consecuencias desastrosas, sobre todo en el Val di Mazara. Allí, la defensa de la identidad musulmana, llevada hasta el sacrificio extremo y respondida con el exterminio y la deportación, infligió heridas mortales a la red de asentamientos, anulando decenas de rihal y manzil, además de algunos qih, grandes asentamientos fortificados de altura. Incluso comparándola con las dos grandes conquistas del siglo IX y XI, la "reconquista federiciana" del interior de Sicilia Occidental, fue un evento particularmente dramático y destructivo. El resultado de la represión dirigida por el suevo, fue el desierto, la despoblación de áreas vastísimas del Val di Mazara, punteadas a partir de 1250 sólo por algunos asentamientos salvados por su precoz latinización.

Para el autor, si por algo debe ser recordado Federico II es por este desastre. La eliminación de la comunidad musulmana llevó a la crisis y a la desaparición del campesinado dependiente, provocando la decadencia de la jerarquía entre asentamiento fortificado y asentamiento abierto: fue el preludio de posteriores abandonos de aldeas y de la concentración de la población siciliana en asentamientos amurallados vigilados por fortalezas.

El interesante estudio de Maurici se enmarca dentro de un ámbito de reflexión que ha planteado un exhaustivo debate historiográfico, sobre todo en Italia: La existencia o no de continuidad entre el asentamiento de la Antigüedad tardía y el de la Alta Edad Media, aunque éste tiende a circunscribirse al fenómeno urbano, mientras que Maurici va más allá, analizando tanto la tipología como la distribución de los asentamientos en el territorio, y la incidencia que tuvieron en ambos los diferentes procesos de encastillamiento.

El autor, como hemos visto, es un firme seguidor de la corriente "continuista", y esto a pesar de que en Sicilia no se puede hablar, en la Alta Edad Media, de un largo y lento proceso de transición social, ya que en este período, fueron tres formaciones sociales sustancialmente diversas las que ocuparon la isla, y en dos ocasiones tras una larga y violenta conquista. Es bastante sorprendente que el modelo de organización territorial impuesto por Bizancio permanezca invariado durante la dominación musulmana y soporte incólume el desembarco normando.

Tal vez, y esgrimiendo uno de los argumentos fundamentales en los que se apoyan los historiadores italianos reacios al continuismo, el autor confunde continuidad con permanencia e insiste en la primera apoyándose en la segunda. No hay duda, Maurici lo demuestra, hubo una "permanencia física" de muchos de los asentamientos bizantinos en etapa musulmana y normanda, y aun más: sólo basta mirar un mapa geográfico de la Sicilia actual para ver que muchos de ellos siguen allí: Mesina, Siracusa, Ragusa, Palermo, Enna, Taormina, Cefalú... Sin embargo, no creo que nadie se atreva a aseverar que el esquema general del asentamiento en la Sicilia de la $\|^{\text {a }}$ República Italiana esté constituido "esencialmente por las ciudades portuarias y por las acrópolis de la Sicilia bizantina y por lo tanto, antigua". 
Desde luego, Maurici es honesto al advertir que falta absolutamente un análisis del territorio basado en el registro arqueológico, o más exactamente, falta aun el propio registro. Aunque los primeros datos parecen evidenciar una dinámica del poblamiento mucho más compleja que la que explica el autor con sus sucesivos "encastellamientos estatales".
A pesar de todo el libro de Maurici es sin duda un análisis riguroso que abre enormes posibilidades de investigación, necesario para completar nuestro conocimiento de la organización del territorio en el período altomedieval en ámbito mediterráneo.

Eva Ma Alcázar Hernández. 